Comparative Philosophy Volume 8, No. 1 (2017): 1

Open Access / ISSN 2151-6014

www.comparativephilosophy.org

\title{
EDITOR'S WORDS
}

The current issue (volume 8, no.1, January 2017) consists of two parts: besides its regular "Articles" part containing four peer-reviewed articles, it also includes a "Constructive-Engagement Dialogue" section marking the tenth anniversary of the constructive-engagement project "Searle's Philosophy and Chinese Philosophy" (the conference held at Hong Kong University of Science and Technology in 2005, and the anthology volume published by Brill in 2008): it includes five authors' furtherengagement articles, in response to Searle's "reply" comments on their contributing essays in the volume. Let me say something more about this section. Around ten years ago, this project is actually a sister project with the nearly concurrent "constructive-engagement" project "Davidson's Philosophy and Chinese Philosophy"; the latter project had been planned to take the similar engaging format with Davidson's prospective replies to the contributions as well as his oral engaging dialogue on the scene of its Beijing conference. However, the SARS outbreak in Beijing in spring 2003 forced us to postpone the 2003 summer conference event to the next year; Davidson thus changed his 2003 summer schedule to carry out his knee-replacement operation; his passing away due to the operation was unfortunate and prevented the direct "constructive engagement" opportunity like the one we have with Searle. So we especially value various aspects of this constructive-engagement opportunity with Searle: Searle not only effectively responded to all the speakers' engaging presentations in the two-day conference in Hong Kong (we can still vividly remember how John was exhausted after giving two days' worth of replies to all the speakers), but also has given his very valuable and thought-stimulating "reply" writings to all the contributors of the volume. In this way, all the volume contributors and the conference participants have deeply treasured and appreciated the engaging opportunity with him. These contributions to this section collectively show such appreciation through further philosophical engagement. To my knowledge, Searle has loved this project's emphasis on the critical engagement of his thought rather than mere celebration. I remember that, in 2004 when I first talked with him about this "engagement" idea explaining to him that we then didn't have secured funding to cover his travel expenses for participating in the Hong Kong conference, although we endeavored to have it; so I asked him whether he still would like to go using his own resources; Searle's answer is a firm "yes" because he likes the challenge and engagement, especially since these challenge and engagement resort to relevant rich resources from both Western and Chinese philosophical traditions.

Bo Mou

January 2017 